\title{
Erratum to: Concerning the capability of monitoring the condition of coal bed by tomography based upon the representation of object model using Chebyshev polynomials
}

\author{
Larisa Nazarova ${ }^{1 *}$, Leonid Nazarov ${ }^{1}$, Maxim Protasov ${ }^{1}$, Anton Panov ${ }^{1}$ and Petr Konichek ${ }^{2}$ \\ ${ }^{1}$ The Institute for Problems of Integrated Development of the Subsurface named after Academician N.V. Melnikov of RAS, Moscow, \\ Russia \\ ${ }^{2}$ Institute of Geonics of the Czech Academy of Science, Ostrava-Poruba, Czech Republic
}

Original article: E3S Web of Conferences 56, 01016 (2018), https://doi.org/10.1051/e3sconf/20185601016

The authors of the article should be replaced by the following text:

Larisa Nazarova ${ }^{1 *}$, Leonid Nazarov ${ }^{1}$, Maxim Protasov $^{1}$, Anton Panov ${ }^{1}$ and Petr Konicek ${ }^{2}$ 